\title{
Second trimester termination of pregnancy complicated with multiple fetal abnormalities and also placenta percreta
}

Sir,

We read with great interest the article by Matsuzaki S and et al., ${ }^{1}$ in which the authors presented a case series named "Successful management of placenta percreta by cesarean hysterectomy with transverse uterine fundal incision". The frequency of placental implantation abnormalities is progressively increasing all over the world, in parallel to the increase in the number of caesarean deliveries. Although rare, placenta percreta is the most significant abnormal implantation, which may pose a serious risk with respect to morbidity and mortality for the mother and the baby. ${ }^{2}$ The depth of placental invasion can reach as far as the serosa of the uterus and sometimes even neighbouring organs. Antenatal diagnosis and surgical approach are very important for the management of this disease. ${ }^{3}$ In our case, hysterotomy was planned for a 24year old G2P1 patient at 18 weeks' gestation with a diagnosis of placenta fully closing the cervical os and multiple fetal anomalies. The patient had a history of caesarean delivery before. During the operation, infiltration of the placenta into the lower segment of the uterus was evident, reaching as far as the serosa (Figure 1). The placenta was left within the uterus after the fetus had been removed. The patient was discharged with a prescription of weekly beta-hCG and ultrasound followup visits were scheduled. At the postoperative day 38 , the patient admitted to our clinic with high fever $\left(39.3^{\circ} \mathrm{C}\right)$ and antibiotic treatment was initiated: sulbactam/cefoperazone $1 \mathrm{~g}$ and ornidazole $500 \mathrm{mg}$ intravenously. An abundant vaginal bleeding started within one day. The patient was taken to the operating room due to hemodynamic impairment $(\mathrm{Hb}: 5.5 \mathrm{~g} / \mathrm{dl}$, Hct: 15.6) and necrotic placenta was manually removed almost completely under abdominal ultrasound monitoring through the cervix dilated approximately to 3 $\mathrm{cm}$. Since the bleeding continued, tamponade was performed using a no.18 Foley catheter placed into the uterine cavity with its balloon filled with $50 \mathrm{cc}$ saline solution. The patient received 18 units of erythrocyte suspension, 14 units of fresh frozen plasma, and 2 units of thrombocyte transfusion in total. The patient was discharged on the third postoperative day. In conclusion, since placenta percreta is very rare during early gestational weeks, information on clinical management of these cases is limited. ${ }^{4}$ Placenta percreta in early gestational weeks may have a life-threatening clinical course similar to that at late gestation, as in our case. In placenta percreta cases at early gestation, conservative management by leaving the placenta in situ after hysterotomy and delivery of the fetus, and then vaginal removal of the necrotic placenta in case of bleeding or infection, which may require an intervention with balloon tamponade if haemorrhage persists, can all be alternatives to hysterectomy in young patients or in those with a desire for fertility.

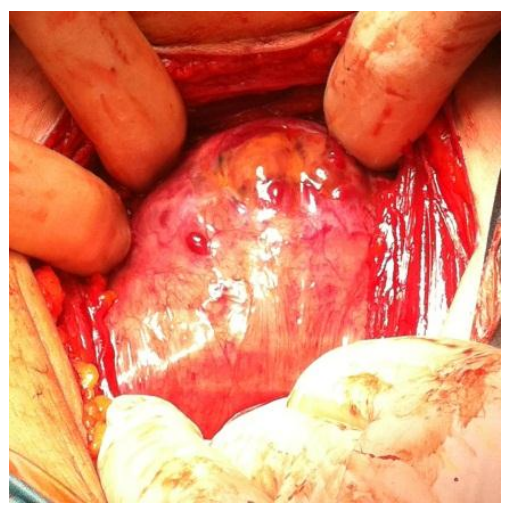

Figure 1: Intraoperative appearance of the placental invasion into the lower segment of the uterus, reaching as far as the serosa.

\section{Ali Babacan ${ }^{1 *}$, Ali Yılmaz, Yaşam Kemal Akpak ${ }^{2}$, Ercüment Müingen ${ }^{1}$, İsmet Gün ${ }^{1}$, Vedat Atay ${ }^{1}$}

${ }^{1}$ Department of Obstetrics and Gynaecology, GATA Haydarpaşa Training Hospital, Istanbul, Turkey ${ }^{2}$ Department of Obstetrics and Gynaecology, Ankara Mevki Military Hospital, Ankara, Turkey

*Correspondence to: Dr. Ali Babacan, E-mail: ababacan_@hotmail.com

\section{REFERENCES}

1. Matsuzaki S, Yoshino K, Kajimoto E, Tanaka Y, Mimura K, Kanagawa $T$, et al. Successful management of placenta percreta by cesarean hysterectomy with transverse uterine fundal incision. Int J Reprod Contracept Obstet Gynaecol. 2014;3:447-9. 
2. Fitzpatrick K, Sellers S, Spark P, Kurinczuk JJ, Brocklehurst $\mathrm{P}$, Knight $\mathrm{M}$. The management and outcomes of placenta accreta, increta, and percreta in the UK: a population-based descriptive study. BJOG. 2014;121:62-71.

3. Wortman AC, Alexander JM. Placenta accreta, increta, and percreta. Obstet Gynaecol Clin North Am. 2013;40:137-54.
4. Wong VV, Burke G. Planned conservative management of placenta percreta. J Obstet Gynaecol. 2012;32:447-52.

DOI: $10.5455 / 2320-1770 . i j r \operatorname{cog} 20141264$

Cite this article as: Babacan A, Yilmaz A, Akpak YK, Müngen E, Gün İ, Atay V. Second trimester termination of pregnancy complicated with multiple fetal abnormalities and also placenta percreta. Int $\mathbf{J}$ Reprod Contracept Obstet Gynecol 2014;3:1167-8. 